\section{Mechanical Behavior of a Twip Steel (Twinning Induced Plasticity)}

\author{
Alberto Monsalve ${ }^{1}$, Flavio De Barbieri ${ }^{1}$, Mauricio Gómez ${ }^{1}$, \\ Alfredo Artigas ${ }^{1}$, Linton Carvajal ${ }^{1}$, Konstantin Sipos ${ }^{1}$, \\ Oscar Bustos ${ }^{1}$, Juan Pérez-Ipiña ${ }^{2}$
}

\footnotetext{
${ }^{1}$ Departamento de Ingeniería Metalúrgica, Facultad de ingeniería, Universidad de Santiago de Chile. Santiago, Chile. alberto.monsalve@usach.cl

${ }^{2}$ Facultad de Ingeniería, Universidad del Comahue, Neuquén, Argentina. juan.perezipina@ fain.uncoma.edu.ar flavio.debarbieri@usach.cl,mauricio.gomezbarrena@usach.cl;alfredo.artigas@usach.cl;linton.carvajal@usachc.l; ksiposh@yahoo.com;oscar.bustos@usach.cl
}

\begin{abstract}
1. ABSTRACT
A TWIP steel $(0.65 \% \mathrm{C} ; 22 \% \mathrm{Mn} ; 0.28 \% \mathrm{Cr} ; 0.16 \% \mathrm{Si})$ was produced in the laboratory by melting, casting, hot forging and hot rolling. The relationship between mechanical twinning fraction and mechanical behavior of this steel was studied through tension tests at the following temperatures: $25,300,325,350,375$ and $400^{\circ} \mathrm{C}$. Fracture toughness was measured from $\mathbf{J}$ integral evaluation at temperatures where the principal hardening mechanism is mechanical twinning and dislocation glide $\left(325\right.$ and $375^{\circ} \mathrm{C}$ respectively), for which a set of CT samples were pre-cracked by fatigue and then loaded until fracture in accordance to ASTM 1820. The plastic strain energy absorbed by each sample during crack growth was studied, correlating twinning with the mechanical response of the material, determining a decrease of plastic deformation energy around $375^{\circ} \mathrm{C}$, where the main deformation mechanism is strain hardening by dislocation glide and not mechanical twinning. Results obtained by different mechanical tests show that mechanical twinning activates in a range of stacking fault energy in the range 18 to $50 \mathrm{~mJ} / \mathrm{m}^{2}$.
\end{abstract}

Keywords: Twinning, plasticity, steel, stacking fault, manganese.

\section{1. INTRODUCTION}

Steels which show twinning phenomena during plastic deformation are called TWIP steels. They are completely austenitic at room temperature due to their high manganese contents, which complies the following relationship:

$\% M n+13 \% C \geq 17$

where $\% M n$ and $\% C$ represent their weight contents of $\mathrm{Mn}$ and $\mathrm{C}$ [1]. Usually these steels have a Mn content between 15 and $30 \%$, while carbon contents stays between 0.1 and $0.8 \%$ weight percent. Additionally they can have some alloying elements such as $\mathrm{Al}, \mathrm{Si}, \mathrm{Cr}, \mathrm{Ti}, \mathrm{V}$ and Mo. Each of these elements changes the stacking fault energy (SFE). For example $\mathrm{Al}$ and $\mathrm{Cu}$ raise the SFE; while Si raises it only up to 3\% contents, while higher contents lowers it, and Cr lowers it [2].

It has been proven that the stacking fault energy value establishes the mechanisms of plastic deformation: when SFE is less than $20 \mathrm{~mJ} / \mathrm{m}^{2}$ martensitic transformation is favored. When the SFE is in a 20 to 47 $\mathrm{mJ} / \mathrm{m}^{2}$ range, twinning is favored. At values higher than $47 \mathrm{~mJ} / \mathrm{m}^{2}$ only dislocation glide is active [3]].

In 1976, Olson and Cohen [4] used classical nucleation theory of martensitic transformation to propose a thermodynamic function to represent the SFE. For this the SFE per unit area is expressed in function of the free energy change of the $\gamma \rightarrow \varepsilon$ transformation $\Delta G^{\gamma \rightarrow \varepsilon}$, of the deformation energy $E^{\text {def }}$ and of the surface energy $\sigma$. The proposed theory also considers the molar density of the $\{111\}$ crystallographic planes and the fault thickness. The model prescribes that depending of the $\Delta \mathrm{G}^{\gamma \rightarrow \varepsilon}$ value and the change of free energy of the martensitic transformation which depends mainly of the chemical composition and the temperature, a value of the SFE can be obtained to favor twinning. 
Other aspects studied in TWIP steels, are the influence of $\% \mathrm{C}$ on twinning, the effect of dynamic strain aging, the role of twinning on deformation hardening, the parameters which raise yield strength, recrystallization kinetics and texture formation.

Nevertheless their mechanical behavior on fatigue and fracture require further insight. On this subject it is important the works of Hamada et al. [-ㄱ] Niendorf et al. [ $\underline{8}, \underline{9}]$, who studied the effect of previous deformation on the response to fatigue and crack growth of TWIP steels. Yet, work has to be done to explain the relationship between twinning and fatigue fracture for this type of steels. There is not information about fracture mechanics of this kind of steels $\left(K_{I C}, J_{I C}\right)$.

The aim of this study is to characterize the fracture response to fracture of a TWIP steel, correlating the presence of twins to this mechanical behavior measured through the calculation of the $\mathrm{J}$ max. parameter

\section{MATERIALS AND METHODOLOGY}

The chemical composition of the steel is shown in table 1

Table 1: Chemical composition of the TWIP steel (weight \%).

\begin{tabular}{l|l|l|l|l|l|l|l|l|l|l}
\hline \%C & $\% \mathrm{Si}$ & $\% \mathrm{Mn}$ & $\% \mathrm{Cr}$ & $\% \mathbf{N i}$ & $\% \mathrm{~V}$ & $\% \mathrm{Cu}$ & $\% \mathrm{Sn}$ & $\% \mathbf{N}$ & $\% \mathrm{P}$ & $\% \mathbf{S}$ \\
\hline 0.65 & 0.162 & 22.14 & 0.028 & 0.043 & 0.05 & 0.028 & 0.035 & 0.03 & 0.06 & 0.007 \\
\hline
\end{tabular}

Melting of the steel was carried out in an induction furnace, casting a $100 \mathrm{~mm}$ wide, $100 \mathrm{~mm}$ thick and $320 \mathrm{~mm}$ long ingot, weighing $25 \mathrm{kgf}$. The ingot was forged at $1,200^{\circ} \mathrm{C}$ to a $20 \mathrm{~mm}$ thick plate. Specimens $300 \mathrm{~mm}$ per $100 \mathrm{~mm}$ and $20 \mathrm{~mm}$ thick were cut and homogenized at $1,250^{\circ} \mathrm{C}$ during $40 \mathrm{~min}$, then hot rolled at temperatures between 1,100 and $910^{\circ} \mathrm{C}$, down to $15 \mathrm{~mm}$ thickness. The rolled steel was quenched in a salt-bath at $350^{\circ} \mathrm{C}$, holding it for $10 \mathrm{~min}$, and subsequently cooling it to room temperature in calm air. Cylindrical tensile test specimens of $12.5 \mathrm{~mm}$ diameter with the length parallel to the rolling direction were machined.

Fracture toughness tests were carried out at the following temperatures: $25-300-325-350-375-400^{\circ} \mathrm{C}$, measuring yield strength, ultimate tensile strength and total elongation to fracture. As the use of linear voltage displacement transducers at high temperatures is not possible, strain measurement was made on the displacement of the horizontal beams of the tensile machine. A total of three samples were used for each temperature.

Compact Tension (CT) specimens were also prepared. Fatigue pre-cracking and fracture of the specimens were done according to ASTM 1820 . Testing was carried out at 25,325 and $375^{\circ} \mathrm{C}$, calculating the $\mathrm{J}_{\max }$ value for each case. Two samples for each temperature were used.

Tensile tests on pre-cracked compact tension specimens were carried out according to ASTM 1820. Figure 1 shows the geometry and size of the test specimen used.

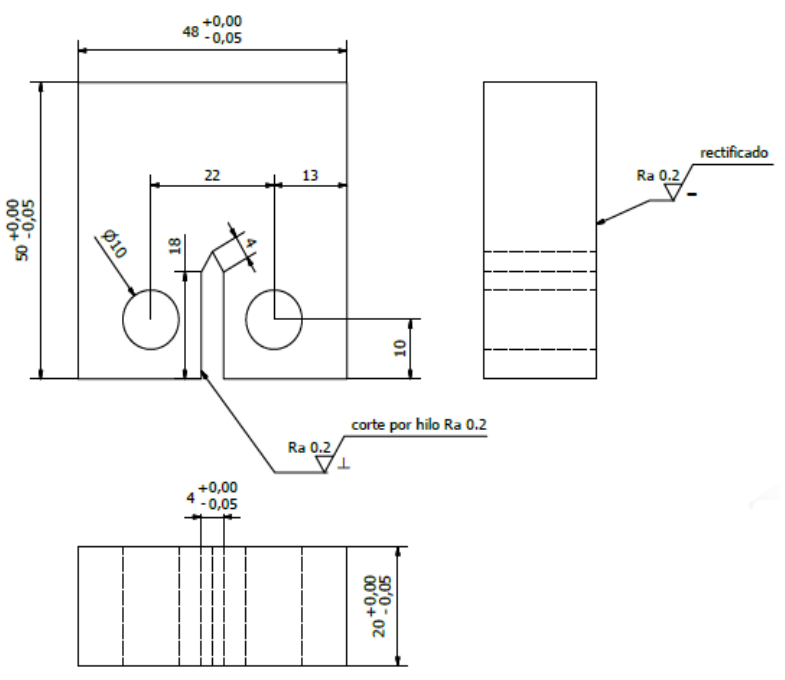

Figure 1: Size of the used CT specimens.

These CT test specimens were pre-fissured with a $5 \mathrm{~mm}$ crack in a resonant fatigue machine using a 
static load of 5,000 N, and a variable cyclic load of 5,000 $\mathrm{N}$ between minimum and maximum. Then the specimens were tensile loaded until fracture at a speed of $1 \mathrm{~mm} / \mathrm{min}$ in the tensile test machine. These specimens were tested at three different temperatures, $25^{\circ} \mathrm{C}, 325^{\circ} \mathrm{C}$ and $375^{\circ} \mathrm{C}$ in an electric resistance furnace. These three temperatures were chosen to get data to calculate the $\mathrm{J}_{\max }$ values for the two hardening mechanisms, mechanical twinning and dislocation glide.

In the fracture tests carried out on these CT samples, the applied load versus displacement was registered. Tthe maximum load was extracted, which corresponds to a technological parameter for comparing similar conditions for stable crack growth. In these steels with high ductility, when the maximum load is attained, there is no sudden unstable crack growth, the crack grows progressively at a controlled stable rate.

\section{RESULTS}

\subsection{Metalographic analysis}

Figure 2 shows the steel microstructure after tensile testing at $25,325,375$ and $400^{\circ} \mathrm{C}$. As expected, twinning density decreases as testing temperature increases (zones marked with red circles). This phenomenon is explained considering that the SFE value changes, and therefore the presence of mechanical twins decrease.

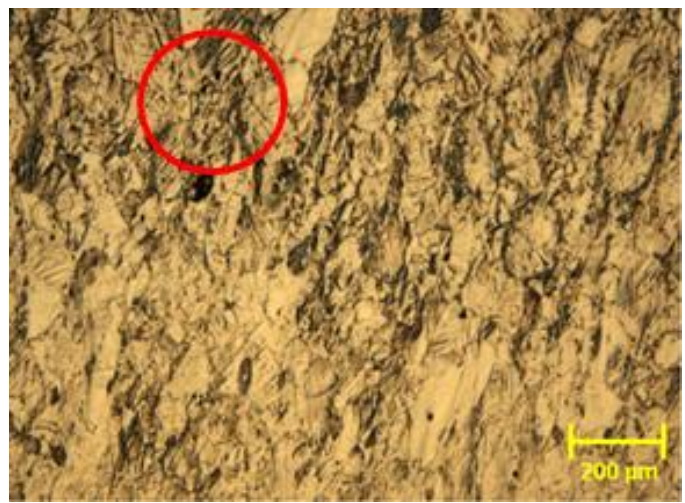

(a)

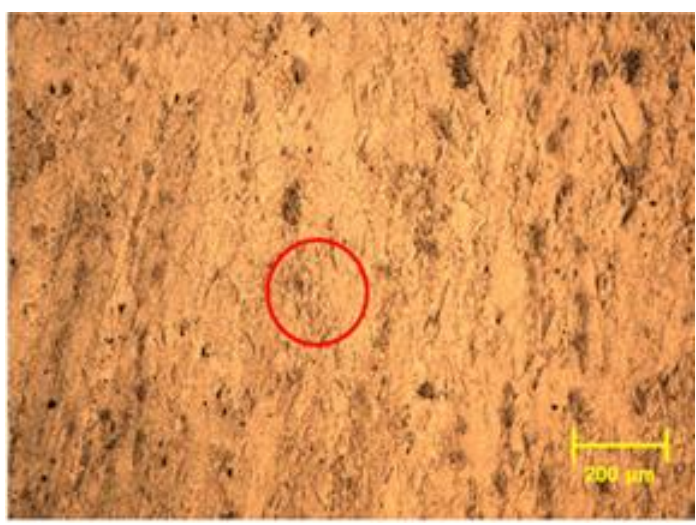

(c)

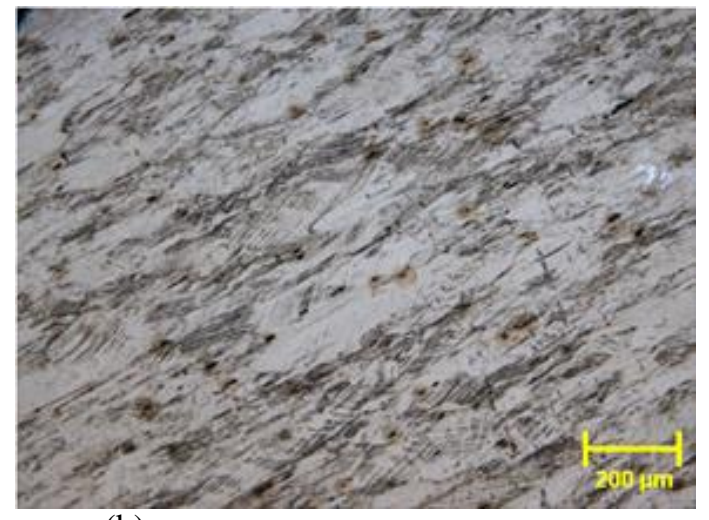

(b)

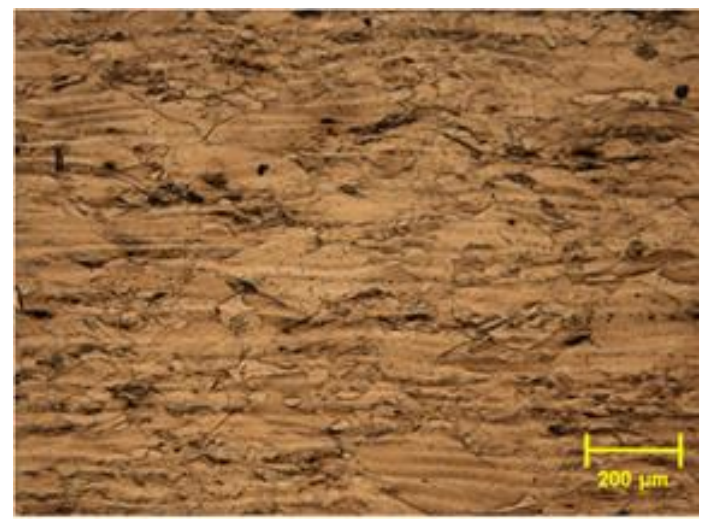

(d)

Figure 2: Microstructure after tensile testing at a) $25^{\circ} \mathrm{C}$; (b) $325^{\circ} \mathrm{C}$; (c) $375^{\circ} \mathrm{C}$; (d) $400^{\circ} \mathrm{C}$.

X-ray diffraction technique was used in order to quantify the twinning fraction, by means of the peak profile analysis. This analysis was carried out applying Rietveld method, using MAUD free license software.

\subsection{Tension tests}

Tension tests were carried out at different temperatures, to verify in which ranges twinning was present. It was determined that over $375^{\circ} \mathrm{C}$ deformation through twinning was practically absent. 
Figure 3 shows a decrease of yield strength and ultimate tensile strength (UTS) as test temperature increases. Elongation to fracture has high values, mostly due to the presence of both deformation mechanisms of twinning and dislocation glide. It clearly shows the influence of the different deformation mechanisms as temperature raises. The value of elongation depends strongly on these mechanisms. For example, at a $400^{\circ} \mathrm{C}$ there is practically no mechanical twinning and therefore elongation is exclusively due to dislocation gliding. Elongations at $25^{\circ} \mathrm{C}$ and $300^{\circ} \mathrm{C}$ are lower and are a product of the combination of mechanical twinning, dynamic strain aging and dislocation glide. Finally, between $325^{\circ} \mathrm{C}$ and $350^{\circ} \mathrm{C}$, mechanical twinning is the main deformation mechanism, as dynamic strain aging disappears at a temperature of $250^{\circ} \mathrm{C}$, due to the fact that Portevin - Le Chatelier effect is not present at $300^{\circ} \mathrm{C}$, as shown in Figure 2.

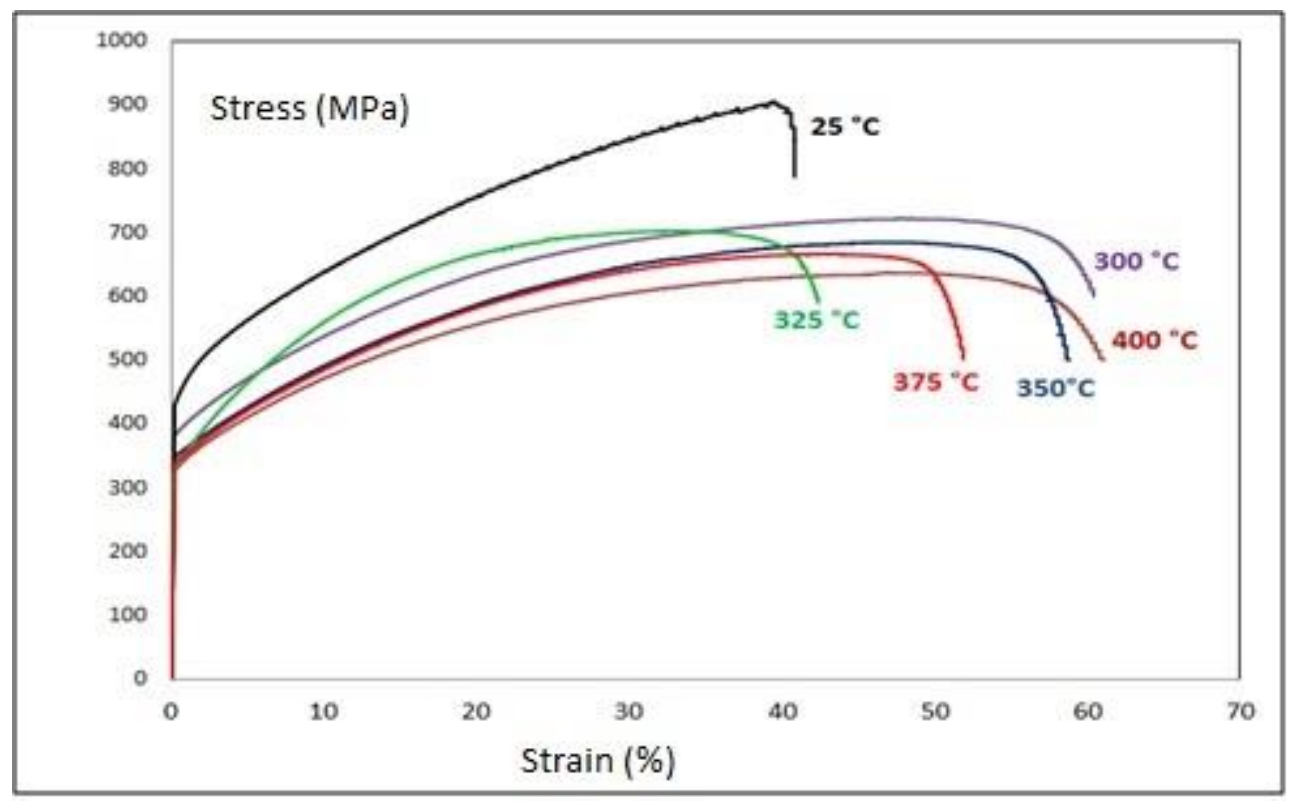

Figure 3: Tensile test curves at different temperatures

\subsection{Fracture toughness test}

Table 2 shows the values of $J$ elastic $\left(J_{e l}\right), J$ plastic $\left(J_{p l}\right)$ and $J$ maximum $\left(J_{\text {max }}\right)$ obtained. Theory tells us that a steel that has only one hardening mechanism will have a $J$ value, representative of the energy for crack growth, which increases with temperature due to the increase of ductility. Nevertheless the measured $\mathrm{J}$ integral value for a TWIP steel is higher at $325^{\circ} \mathrm{C}$ than at $375^{\circ} \mathrm{C}$. The decrease of $\mathrm{J}_{\max }$ can be explained by the fact that dislocation glide is present at all tested temperatures, but mechanical twinning is only present up $325^{\circ} \mathrm{C}$, so at temperatures higher than $325^{\circ} \mathrm{C}$, dislocation glide is the unique active deformation mechanism. At $325^{\circ} \mathrm{C}$ mechanical twinning absorbs deformation energy, increasing fracture toughness.

Table 2: Values of $J_{e l}, J_{p l}$ and $J_{\max }$ at different temperatures in $\left(\mathrm{kJ} / \mathrm{m}^{2}\right)$.

\begin{tabular}{c|c|c|c}
\hline Temperature $\left({ }^{\circ} \mathbf{C}\right)$ & $J_{e l}$, & $J_{p l}$ & $J_{\max }$ \\
\hline 25 & 115.3 & 4358.5 & 4473.7 \\
\hline 325 & 167.7 & 8323.8 & 8491.5 \\
\hline 375 & 120.9 & 7572.6 & 7693.5 \\
\hline
\end{tabular}

\subsection{Micrographic analysis of the $\mathrm{J}$ integral test on the scanning electron microscope (SEM).}

Figure 4 shows two images recorded in the SEM, at $325^{\circ} \mathrm{C}$, both by retro-dispersed electrons (a) and secondary electrons (b). This figure shows that at temperatures of $350^{\circ} \mathrm{C}$ or higher there is a very small presence of twinning. The surface close to the crack tip where mechanical twinning is clearly shown. In figure 5, the im- 
ages show the fractured samples at $375^{\circ} \mathrm{C}$, where no mechanical twinning is observed.

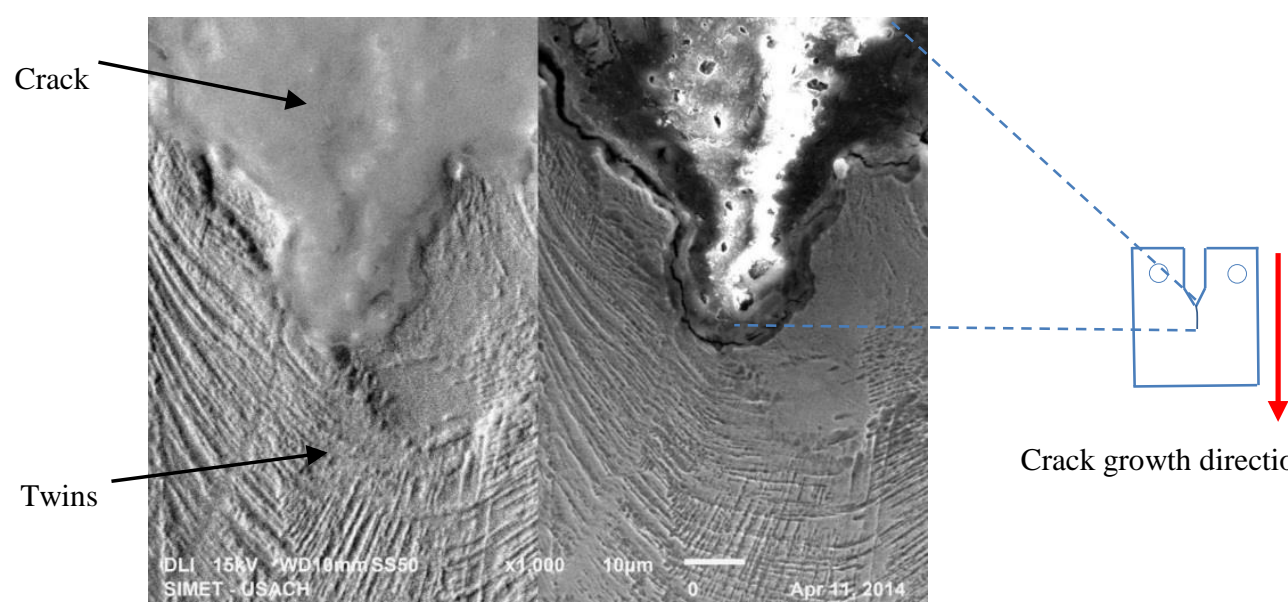

(a)

(b)

Figure 4: SEM Images of the surface the of the fractured sample at $325^{\circ} \mathrm{C}$ a) retro-dispersed electrons (b) secondary electrons .

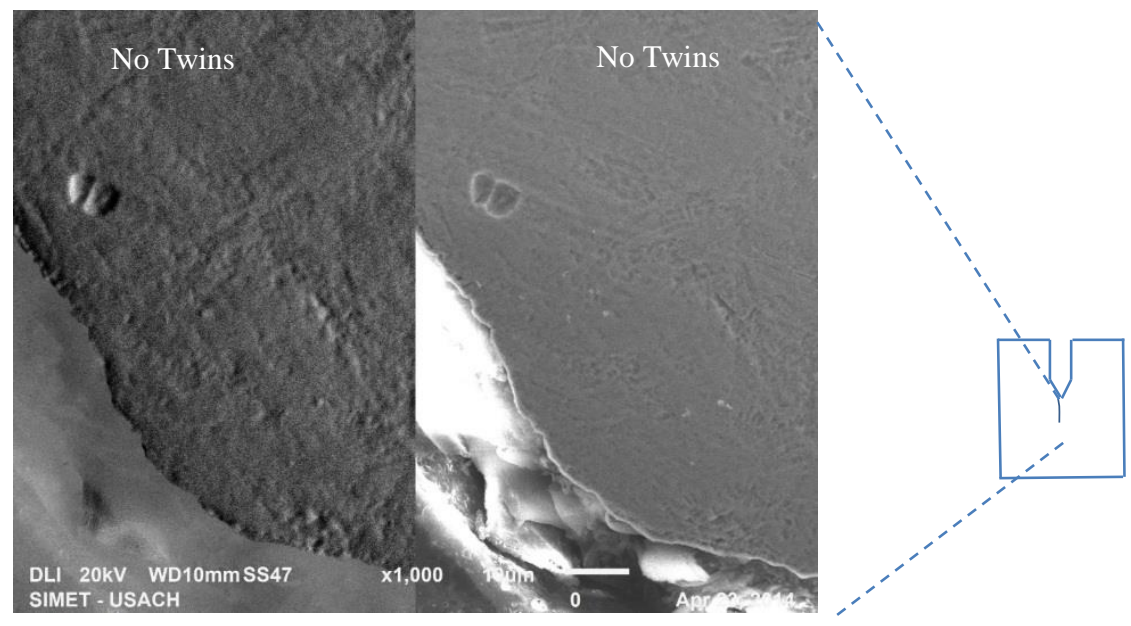

(a)

(b)

Figure 5: SEM Images of the surface of the fractured sample at $375^{\circ} \mathrm{C}$ a) retro-dispersed electrons (b) secondary electrons.

\section{DISCUSSION}

There is a competition between both mechanisms of deformation: twinning and dislocation glide. At low temperatures, deformation by twinning is the main mechanism. At high temperatures, deformation by dislocation glide is possible. This is evident in figure 1 , nevertheless, the influence of temperature must be considered, due to the effect in the decrease of internal friction and then of the dislocation glide. From the metallographic analysis it was possible to conclude that twinning was observed until $325^{\circ} \mathrm{C}$, while at temperatures higher than $350^{\circ} \mathrm{C}$, twinning does not appear. For this reason, an experiment at two temperatures was carried out $\left(325\right.$ and $\left.375^{\circ} \mathrm{C}\right)$ in order to study the effect of temperature on the fracture behavior of the steel. The authors have measured the twinning fraction at different temperatures, finding a value of $4.14 \times 10^{-6}$ at $325^{\circ} \mathrm{C}$ and $2.4 \times 10^{-9}$ for $375^{\circ} \mathrm{C}$. These values of twinning fraction are typical at these temperatures. As can be deduced, a strong decrease in the twinning fraction is measured when temperature increase. The measurement of the twinning fraction was made by means of X-ray diffraction, taken into account the shape and slip of the peaks in the diffractograms obtained [10].

The parameter used to characterize the fracture behavior of the TWIP steel was $\mathrm{J}_{\max }$. The ASTM 1820 standard was applied to compute $J_{e l}, J_{p l}$ and $J_{\max }$, by means of the data obtained from the register of load 
versus displacement in the fracture tests. The higher values of $J_{\max }$ corresponds to the experiment made at $325^{\circ} \mathrm{C}$; the lower value was obtained at $25^{\circ} \mathrm{C}$. These measurements confirm that the maximum toughness is related to that temperature with a high value of twinning fraction. This can be explained by the absorption of energy produced by twinning, phenomena that added to the increment of ductility with temperature, produces a maximum in $J_{\max }$ at $325^{\circ} \mathrm{C}$.

The optical and electronic microscopy analyses confirm the previous observations. In figures 4 and 5, it is possible to observe the fracture surface of the steel tested at 325 and $375^{\circ} \mathrm{C}$. In the first case, the fracture surface exhibits a lot of twins, however at $375^{\circ} \mathrm{C}$ the fracture surface has no evidence of twins, confirming that twinning disappear at $375^{\circ} \mathrm{C}$ and the high value of $J_{\max }$ is due to the presence of twins.

\section{CONCLUSIONS}

a) The TWIP phenomenon was verified through metallographic analysis of the steel after tensile testing at different temperatures. Mechanical twinning is present up to $325^{\circ} \mathrm{C}$. Over this temperature dislocation glide is the only deformation mechanism operating.

b) The values of $\mathrm{J}_{\mathrm{el}}, \mathrm{J}_{\mathrm{pl}}$ y $\mathrm{J}_{\max }$ increase with temperature between 25 y $325^{\circ} \mathrm{C}$, while these values decrease when the temperature raises to $375^{\circ} \mathrm{C}$, which can be attributed to energy absorption by the mechanical twinning phenomena at lower temperatures.

\section{ACKNOWLEDGEMENTS}

The authors wish to thank DICYT USACH and the 1140241 FONDECYT project.

\section{BIBLIOGRAPHY}

[1] BOUAZIZ, O., ALLAIN, S., SCOTT, C.P., et al, "High manganese austenitic twinning induced plasticity steels: A review of the microstructure properties relantionships", Current Opinion in Solid State and Materials Science, v.15, pp.141-168, 2011.

[2] PARK, K.T., KIM, G., KIM, S.K., et al, "On the transition of deformation model of fully austenitic steels at room temperature", Met. Matter Int., v.16, n.1, pp. 1-6, 2010.

[3] GRASSEL, O., KRUGGER, L., FROMMEYER, G., et al, "High strength Fe-Mn (Al,Si) TWIP/TRIP steels development, properties, application”, Int. Journal of Plasticity, v.16, pp.1391-1409, 2000.

[4] OLSON, G.B., COHEN, M. "A General Mechanism of Martensitic Nucleation: Part I. General Concepts and FCC $\rightarrow$ HCP Transformation", Metallurgical Transactions A, v. 7A, 1897-1904, Dec. 1976.

[5] HAMADA, A.S., KARJALAINEN, L.P., PUUSTINEN, J. "Fatigue behavior of high Mn TWIP steel", Material Science and Engineering A, v. 517, pp.68-77, 2009.

[6] HAMADA, S., KARJALAINEN, L.P., FERRAIUOLO, A., et al., "Fatigue behavior of four high Mn twinning induced plasticity steels", Metallurgical and Materials Transactions A, v. 41A, pp.1102-1108, 2010.

[7] HAMADA, A. S., KARJALAINEN, L.P. "High-cycle fatigue behavior of ultrafine-grained austenitic stainless and TWIP steels", Materials Science and Engineering, v.527, pp. 5715-5722, 2010.

[8] NIENDORF, T., LOTZE, C., CANADINC, D., et al, "The role of monotonic pre deformation on the fatigue performance on a high Mn austenitic TWIP steel", Material Science and Engineering A, v. 499, pp. 518-524, 2004.

[9] NIENDORF, T., RUBITSCHEK, F. MAIER, H., et al., "Frehn, Fatigue crack growth Microstructure relationships in a high Mn austenitic TWIP steel”, Materials Science and Engineering A, v. 527, pp.2412-2417, 2010.

[10] BARBIERI, F. Efecto del maclado mecánico en la tenacidad a la fractura de un acero TWIP, Tesis de D.Sc, Universidad de Santiago de Chile, Santiago Chile, 2014. 